\title{
Cardiac tumors and gastroendoscopy: endoscopic resection of left ventricular tumors
}

Endoscopic techniques have expanded in recent years and now have the potential to be useful not only in digestive diseases but also in diseases usually seen by other departments. Cardiac tumors require surgical resection to prevent tumormediated embolism [1]; however, a left ventriculotomy significantly decreases the ejection fraction [2].

We previously reported two cases of cardiac surgery using rigid scopes [3], but in this case a gastroendoscope was used. The patient was a 73-year-old woman who was diagnosed with a cerebral infarct. Echocardiography detected a mobile mass ( $\mathbf{F i g . 1}$ ), and she was referred to the Department of Cardiovascular Surgery. We decided to use an endoscope to prevent a decrease in ejection fraction; however, the space to perform the procedure was expected to be narrow and would have been insufficient if a rigid scope had been inserted. Therefore, we used a gastroendoscope, which allowed the insertion of devices through the scope.

The procedure was performed via a median full sternotomy and the ascending aorta was opened. The gastroendoscope was inserted into the heart through the aortic valve. The cavity was narrow and the procedure using a rigid scope might have been difficult. The tumor was joined to three chordae tendineae ( $\mathbf{F i g . 2}$ ), which we divided using hot biopsy forceps ( $\vee$ Video 1 ). The tumor was resected without complications and echocardiography revealed no change in the patient's ejection fraction (before, $71 \%$; after, $72 \%$ ). Histological examination revealed a papillary fibroelastoma.

In general, bleeding is a severe adverse event associated with gastrointestinal endoscopic resection [4]. This procedure is however not associated with a risk of bleeding as, even if bleeding is extensive, the blood remains in the systemic circulation.

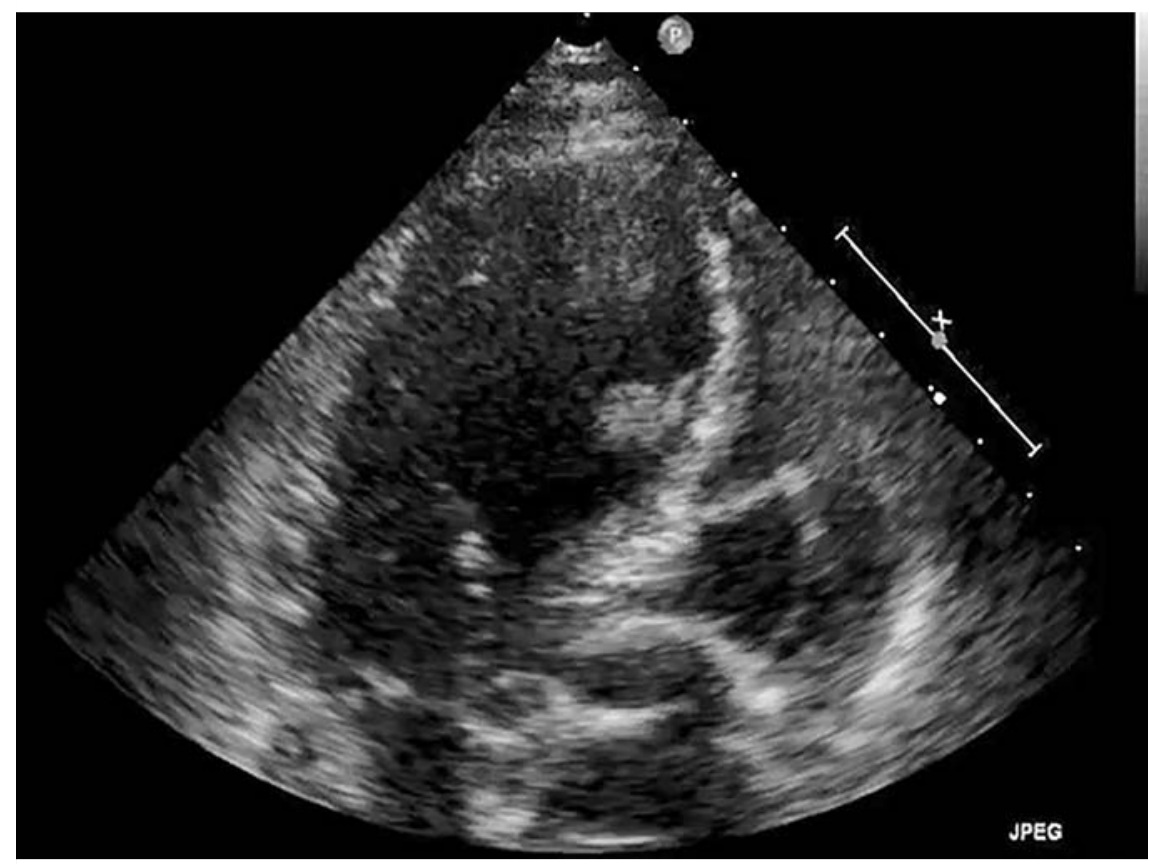

- Fig. 1 Echocardiographic image showing a mobile mass measuring $1.5 \mathrm{~cm}$ in diameter, suggestive of a tumor arising from the ventricular septum of the left ventricle.

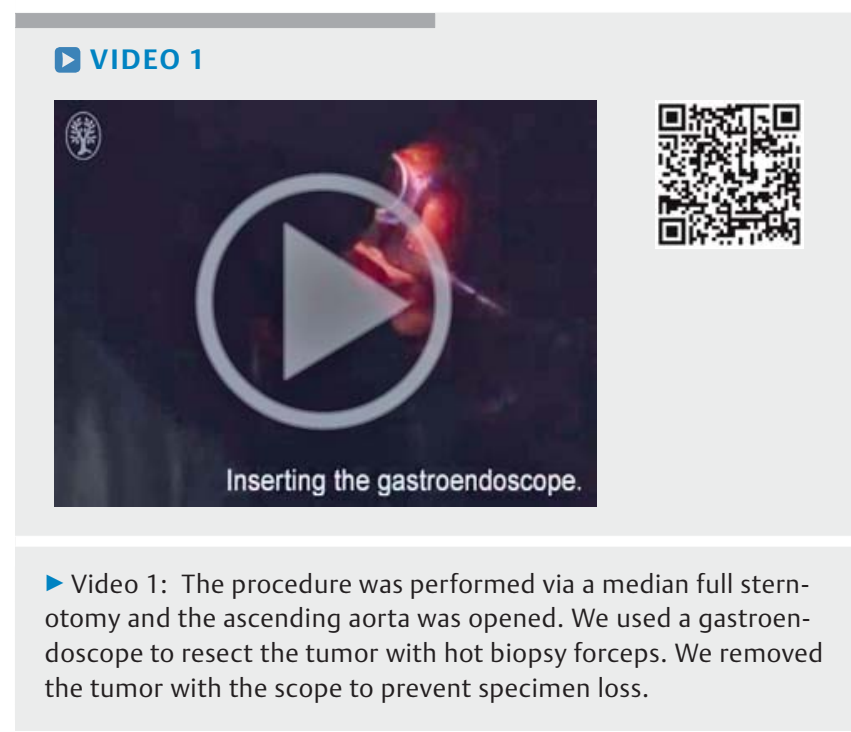



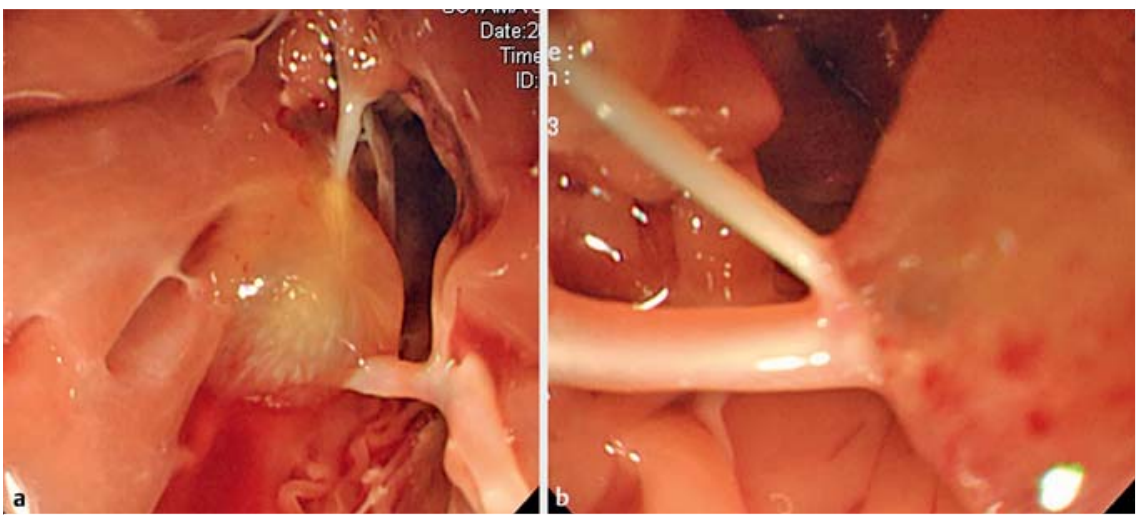

- Fig. 2 Endoscopic views of the tumor showing: a the tumor positioned close to the aortic valve, meaning the space for the procedure was expected to be narrow; $\mathbf{b}$ the tumor combined with the ventricular septum by chordae tendineae.

This is the world's first report of the insertion of a gastroendoscope into the heart. Cardiac tumors and a gastroendoscope would appear to be an amazing combination, and this approach may offer exciting new possibilities for the application of endoscopic techniques.

Endoscopy_UCTN_Code_TTT_1AO_2AN

\section{Competing interests}

None
The Authors

Jun Arimoto' ${ }^{1}$, Takuma Higurashi ${ }^{2}$, Shingo Kato ${ }^{2}$, Shungo Goto ${ }^{1}$, Satoru Suzuki ${ }^{3}$, Atsushi Nakajima², Kazuhiro Atsukawa ${ }^{1}$

1 Department of Gastroenterology, Hiratsuka City Hospital, Hiratsuka, Japan

2 Department of Gastroenterology and Hepatology, Yokohama City University School of Medicine, Yokohama, Japan

3 Department of Cardiovascular Surgery, Hiratsuka City Hospital, Hiratsuka, Japan
Corresponding author

\section{Jun Arimoto, MD}

1-19-1 Minamihara, Hiratsuka, Kanagawa 254-0065, Japan,

junarimoto_junjun@yahoo.co.jp

\section{References}

[1] Cooley DA. Surgical treatment of cardiac neoplasms: 32-year experience. Thorac Cardiovasc Surg 1990; 38: 1-2

[2] Burke RP, Michielon G, Wernovsky G. Videoassisted cardioscopy in congenital heart operation. Ann Thorac Surg 1994; 58: 864 868

[3] Misumi T, Kudo M, Koizumi K et al. Intraoperative endoscopic resection of left ventricular tumors. Surg Today 2005; 35: 1092 1094

[4] Horiuchi A, Nakayama Y, Kajiyama M et al. Removal of small colorectal polyps in anticoagulated patients: a prospective randomizes comparison of cold snare and conventional polypectomy. Gastrointest Endosc 2014; 79: 417-423

\section{Bibliography}

DOI http://dx.doi.org/10.1055/s-0042-122139

Endoscopy 2017; 49: E23-E24

(c) Georg Thieme Verlag KG

Stuttgart · New York

ISSN 0013-726X 